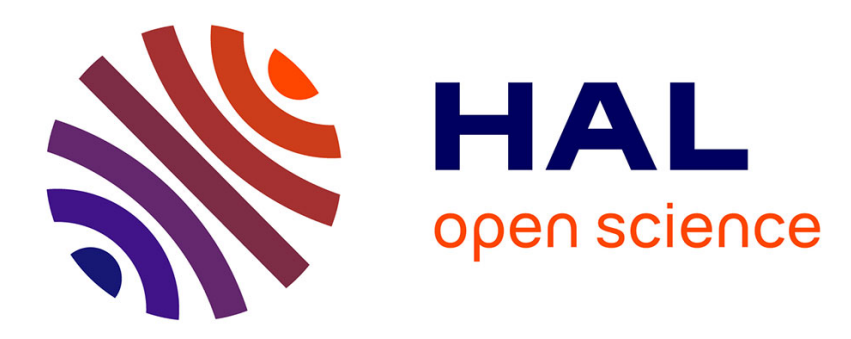

\title{
Cr-Tm and Cr-Er energy transfer in GSAG and YSGG crystals
}

\author{
I. Sorokina
}

\section{To cite this version:}

I. Sorokina. Cr-Tm and Cr-Er energy transfer in GSAG and YSGG crystals. Journal de Physique IV Proceedings, 1994, 04 (C4), pp.C4-521-C4-524. 10.1051/jp4:19944125 . jpa-00252576

\section{HAL Id: jpa-00252576 https://hal.science/jpa-00252576}

Submitted on 1 Jan 1994

HAL is a multi-disciplinary open access archive for the deposit and dissemination of scientific research documents, whether they are published or not. The documents may come from teaching and research institutions in France or abroad, or from public or private research centers.
L'archive ouverte pluridisciplinaire HAL, est destinée au dépôt et à la diffusion de documents scientifiques de niveau recherche, publiés ou non, émanant des établissements d'enseignement et de recherche français ou étrangers, des laboratoires publics ou privés. 


\section{Cr-Tm and Cr-Er energy transfer in GSAG and YSGG crystals}

\section{I.T. SOROKINA}

Technische Universität Wien, Abt. Quantenelektronik und Lasertechnik, Gusshausstr. 27/359, 1040 Wien, Austria

Sensitization of rare-earth doped solid-state lasers by chromium ions can greatly improve their flashlamp-pumped performance. Along with the widely used Cr,Er:YAG and $\mathrm{Cr}, \mathrm{Tm}$ :YAG crystals, the similar systems, based on GSAG (gadolinium scandium aluminum garnet) and YSGG (yttrium scandium gallium garnet) crystals [1,2], are of intense interest currently.

In this paper the results of the systematic study of series of Cr,Tm:GSAG, Cr,Tm:YSGG and Cr,Er:YSGG crystals with Tm and Er concentrations of $2 \times 10^{20}$ $\mathrm{cm}^{-3}$ to $40 \times 10^{20} \mathrm{~cm}^{-3}$ are presented. The dynamics of $\mathrm{Cr}-\mathrm{Tm}$ and $\mathrm{Cr}-\mathrm{Er}$ energy transfer were studied by analysis of $\mathrm{Cr}$ decay kinetics and Er fluorescence build-up at the selective excitation of $\mathrm{Cr}$ ions.

The analysis of $\mathrm{Cr}$ decay curves with the help of computer simulation allowed to identify the mechanisms and the character of energy transfer as well as to evaluate the corresponding microparameters of the transfer in the studied crystals.

The example of $\mathrm{Cr}^{3+}$ fluorescence decay curve in the presence of $\mathrm{Tm}^{3+}$ ions in GSAG crystal is depicted in Fig. 1a. At low concentrations of $\mathrm{Tm}^{3+}\left(\sim 2 \times 10^{20} \mathrm{~cm}^{-3}\right)$ the energy transfer is dipole-dipole, has a statical disordered character and is well described by the following relation:

$$
I(t)=I_{0} \exp \left(-\frac{t}{\tau_{C r}}\right)-\gamma \sqrt{t}
$$

where $I_{0}$ is the normalized initial fluorescence intensity, $\gamma=-4 / 3 \pi^{3 / 2} n_{\mathrm{A}} \sqrt{C_{\mathrm{DA}}}$ is the parameter of the direct static interaction $\mathrm{Cr}^{3+}-\mathrm{Tm}^{3+}, n_{\mathrm{Tm}}$ is the concentration of $\mathrm{Tm}^{3+}$, and $\mathrm{C}_{\mathrm{DA}}$ is the microparameter equal to the probability of $\mathrm{Cr}^{3+}$ and $\mathrm{Tm}^{3+}$ ions interaction at the distance of $1 \mathrm{~cm}$. The quantum efficiency of the energy transfer in this crystal even at low $n_{\mathrm{Tm}}=2 \times 10^{20} \mathrm{~cm}^{-3}$ turned out to exceed $80 \%$.

The same mechanisms of interaction between $\mathrm{Cr}^{3+}$ and $\mathrm{Er}^{3+}$ ions in YSGG crystal have been observed at the $n_{E r}$ up to $2 \times 10^{20} \mathrm{~cm}^{-3}$.

Thus, at low concetrations of $\operatorname{Tm}$ and $\operatorname{Er}\left(2 \times 10^{20} \mathrm{~cm}^{-3}\right)$ the transfer is dipoledipole, which demonstrates Fig. $1 \mathrm{~b}$ (slope is equal to $1 / 2$ ), and has a static disordered character. In this Fig. $\Pi(t)$ is the "energy transfer function" in the following formula, describing the fluorescence decay of donor ions (D) at the relative concentration of acceptor ions $\left(x_{A}\right)$ and donor-acceptor interaction probability $w_{\mathrm{DA}}=C_{D A} / R^{6}$ (for dipole-dipole case):

$$
N_{\mathrm{D}}(t)=N_{\mathrm{D}}(0) \exp \left(-\frac{t}{\tau_{D}}-\Pi(t)\right)
$$

where

$$
\Pi(t)=\sum_{i} \ln \left(1-x_{\mathrm{A}}+x_{\mathrm{A}} e^{-\left(w_{\mathrm{DA}}\right)_{i} t}\right)
$$


At higher concentrations the fast $(\tau<100 \mathrm{~ns})$ energy transfer has been observed.

In Fig. $2 \mathrm{~b}$ the dependence of the part of $\mathrm{Cr}$ ions, rapidly transfering their energy $(\mathrm{P})$, upon the relative concentration of acceptors ( $\mathrm{Tm}$ and $\mathrm{Er}$ ions), is presented (circles). The calculated probabilities of the presence of at least one acceptor in the first (solid line) and the first two (dashed line) nearest coordination shells are also plotted. This probability is equal to $P=1-\left(1-n_{\mathrm{A}}\right)^{p}$, where $n_{\mathrm{A}}$ is the relative concentration of acceptors, $p$ is the number of acceptors in the first $(p=8)$ and in the first two $(p=12)$ coordination shells. It becomes evident, that for both $\mathrm{Tm}$ and $\mathrm{Er}$ ions the good agreement with the experimental data is achieved under the first coordination shell approximation. Thus, the radius of this strong interaction was found to be $\sim 3.5$ $\AA$.

The Cr decay kinetics at the Er concentration of $40 \times 10^{20} \mathrm{~cm}^{-3}$, shown in Fig. 2 a is of special interest. It consists of the two exponential parts. The initial (rapid) part corresponds to the fast energy transfer. About $75 \%$ of all $\mathrm{Cr}^{3+}$ excitations transfer their energy rapidly to $\mathrm{Er}^{3+}$ ions within the first $100 \mathrm{~ns}$. The second (slow with the lifetime $\tau \sim 1.1 \mu \mathrm{s}$ ) part is not described within the dipole-dipole energy transfer model, but it can be satisfactory described within the "excitation trapping" model at the strong interaction of excited $\mathrm{Cr}$ ions with the nearest $\mathrm{Er}$ ions at the ${ }^{4} I_{9 / 2}$ level (with a lifetime of less, than $1 \mu \mathrm{s}$ ). The observed $\mathrm{Cr}$ lifetime turned out to be equal to the calculated one within the mentioned above model of "excitation trapping" [3].

Thus, the energy transfer mechanisms and microparameters of interaction between $\mathrm{Cr}^{3+}$ and $\mathrm{Tm}^{3+}$ ions in GSAG were established. In YSGG:Cr, Er and YSGG:Cr, Tm crystals the "rapid energy transfer" to the $\mathrm{Er}^{3+}$ and $\mathrm{Tm}^{3+}$ ions was investigated. The radius of this strong interaction was found to be $\sim 3.5 \AA$. It was also shown, that in both cases of the energy transfer to $\mathrm{Tm}^{3+}$ and $\mathrm{Er}^{3+}$ ions, the strong interaction occurs within the first coordination shell of $\mathrm{Cr}^{3+}$ ions. The model of the "excitation trapping" between $\mathrm{Cr}^{3+}$ and $\mathrm{Er}^{3+}$ ions at their strong interaction was suggested to describe the $\mathrm{Cr}^{3+}$ fluorescence decay at large concentrations of $\mathrm{Er}^{3+}$ ions $\left(40 \times 10^{20} \mathrm{~cm}^{-1}\right)$.

\section{References}

1. P. Moulton et al, IEEE J. Quantum Electron, QE-24, 960 (1988).

2. E.V. Zharikov et al, Inorg. Mat., 48, 81 (1984).

3. T.T. Basiev et al, JETP, 70, 1225 (1976). 

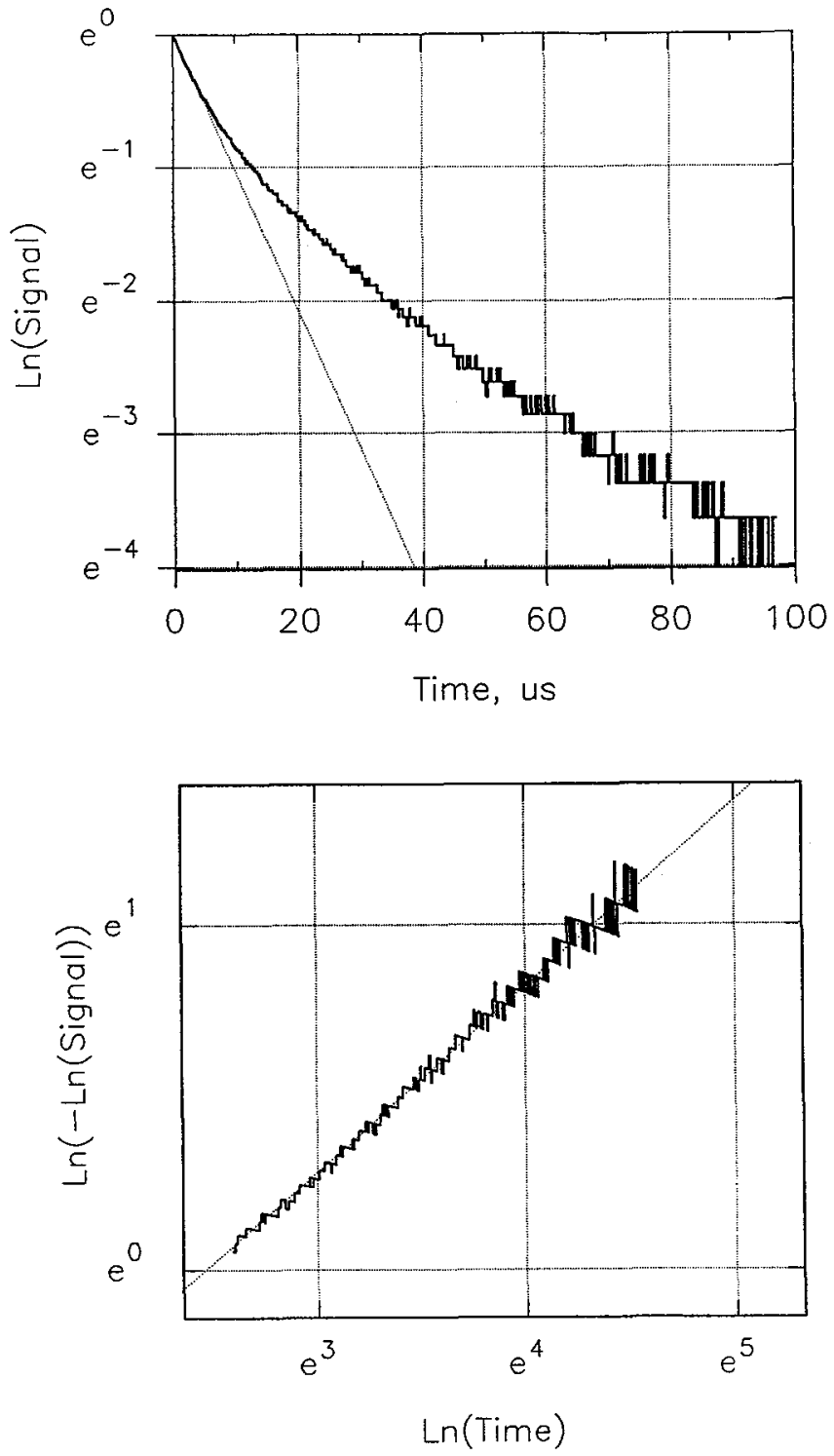

Figure 1: $a$ : The $\mathrm{Cr}^{3+}$ fluorescence decay curve in the presence of $\mathrm{Tm}^{3+}$ ions $\left(n_{\mathrm{Tm}}=\right.$ $2 \times 10^{20} \mathrm{~cm}^{-1}$ ) in GSAG; $b$ : Logarithm of the "energy transfer function" vs. logarithm of time in the same crystal. 


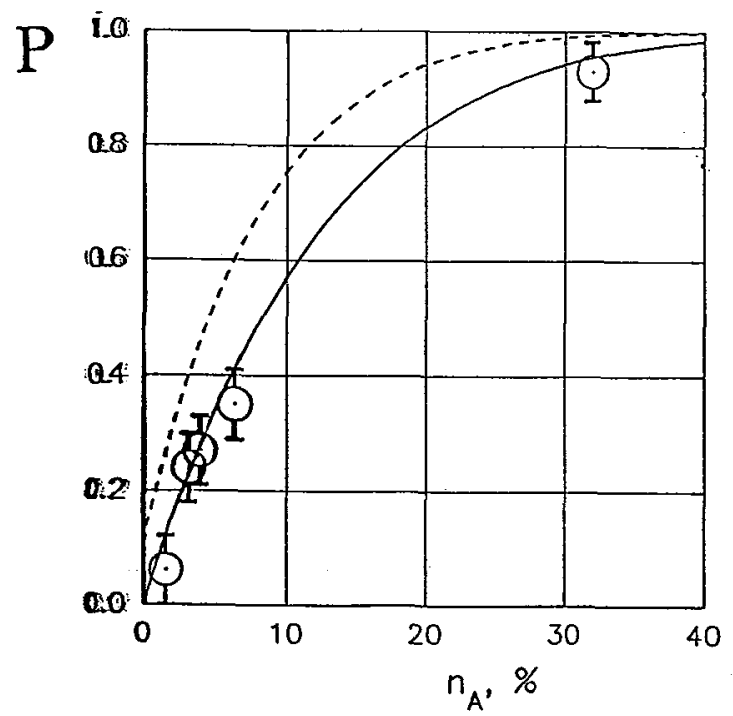

Figure 2: Circles: dependence of the part of $\mathrm{Cr}^{3+}$ ions involved in the "fast energy transfer" to $\mathrm{Er}^{3+}$ and $\mathrm{Tm}^{3+}$ ions $(\mathrm{P})$ on the relative concentration of the latter $\left(n_{\mathrm{A}}\right)$. Solid line: results of the calculations, taking into account the energy transfer only to the first coordination shell. Dashed line: same taking into account both the first and the second coordination shells.

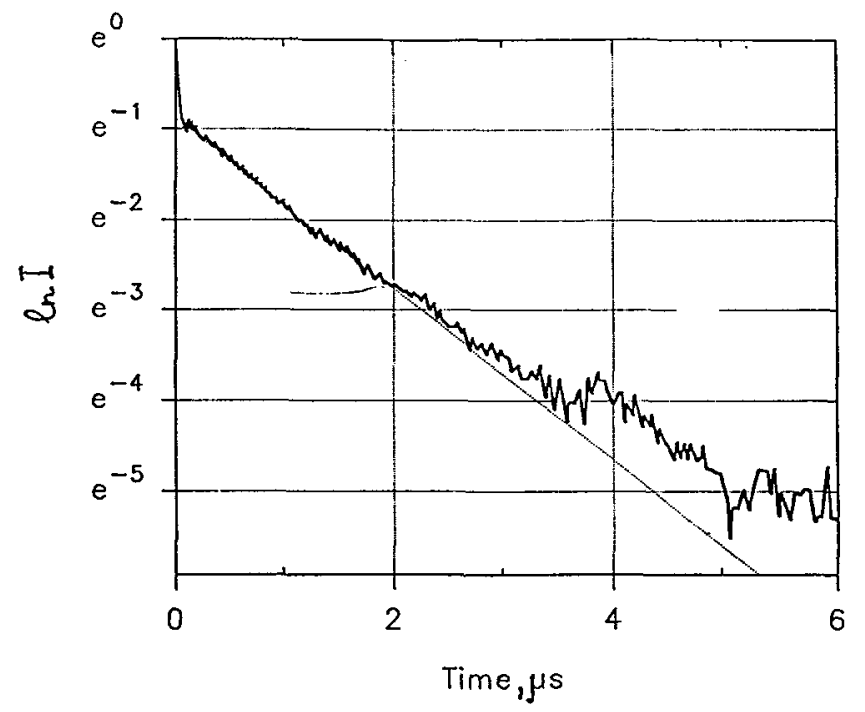

Figure 3: The $\mathrm{Cr}^{3+}$ fluorescence decay in the presence of $\mathrm{Er}^{3+}$ ions $\left(\lambda=740 \mathrm{~nm}, \mathrm{~N}_{\mathrm{Er}}\right.$ $=40 \times 10^{20} \mathrm{~cm}^{-3}$ ). 